\title{
Fast Molecular Beacon Hybridization in Organic Solvents with Improved Target Specificity
}

\author{
Neeshma Dave and Juewen Liu* \\ Department of Chemistry, Waterloo Institute for Nanotechnology, University of Waterloo, \\ 200 University Avenue West, Waterloo, Ontario, N2L 3G1, Canada \\ Email: liujw@uwaterloo.ca, Fax: 519 746-0435
}

Received: July 20, 2010;

Revised Manuscript Received: October 13, 2010

This document is the Accepted Manuscript version of a Published Work that appeared in final form in The Journal of Physical Chemistry B, copyright (C) American Chemical Society after peer review and technical editing by publisher. To access the final edited and published work see http://dx.doi.org/10.1021/jp106754k 


\section{ABSTRACT}

DNA hybridization is of tremendous importance in biology, bionanotechnology, and biophysics. Molecular beacons are engineered DNA hairpins with a fluorophore and a quencher labeled on each of the two ends. A target DNA can open the hairpin to give an increased fluorescence signal. To date, the majority of molecular beacon detections have been performed only in aqueous buffers. We describe herein DNA detection in nine different organic solvents, methanol, ethanol, isopropanol, acetonitrile, formamide, dimethylformamide (DMF), dimethyl sulfoxide (DMSO), ethylene glycol, and glycerol, varying each up to $75 \%(\mathrm{v} / \mathrm{v})$. In comparison to detection in water, the detection in organic solvents showed several important features. First, the molecular beacon hybridizes to its target DNA in the presence of all the nine solvents up to a certain percentage. Second, the rate of this hybridization was significantly faster in most organic solvents compared to water. For example, in $56 \%$ ethanol the beacon showed a 70 -fold rate enhancement. Third, the ability of the molecular beacon to discriminate single base mismatch is still maintained. Lastly, the DNA melting temperature in the organic solvents showed a solvent concentrationdependent decrease. This study suggests that molecular beacons can be used for applications where organic solvents must be involved or organic solvents can be intentionally added to improve the molecular beacon performance.

\section{INTRODUCTION}

DNA hybridization is of tremendous importance in biology, bionanotechnology, and biophysics. ${ }^{1-7}$ The relative ease in DNA synthesis and modification has allowed a variety of DNA probes to be used in genomics, disease diagnosis, bioanalytical chemistry and nanotechnology. ${ }^{8-16}$ Analytical tools including gene chips ${ }^{17}$ polymerase chain reactions, ${ }^{18}$ molecular beacons, ${ }^{15,19}$ and functionalized nanoparticles ${ }^{20}$ have all been developed using DNA hybridization properties. To date, such assays have been almost exclusively performed in aqueous buffers, which could be related to the perception that DNA has poor solubility and stability in organic solvents. As in the case of ethanol, it is routinely used for DNA precipitation and it is well known that ethanol can decrease DNA melting temperature $\left(\mathrm{T}_{\mathrm{m}}\right)$ and facilitate DNA denaturation. ${ }^{21}$ On the other hand, protein enzymes have been systematically studied in organic 
solvents and their applications in making pharmaceutical compounds and fine chemicals have been well documented. ${ }^{22,23}$ Studying DNA hybridization in organic solvents may extend the application of DNAbased tools and assays to many other fields of research, such as the monitoring of organic wastes, ${ }^{24}$ studying chemical reactions in organic solvents with DNA, ${ }^{25}$ and understanding nanomaterials with DNA probes. $^{26}$ In addition, we may gain a better biophysical understanding of DNA hybridization. One important aspect related to practical applications is the kinetics of hybridization where a higher rate of reaction would allow for a quicker sensor response for homogenous assays. For immobilized DNA sensors, however, other kinetic processes such as diffusion may be the rate limiting step.

Using DNA-functionalized gold nanoparticles (AuNPs), we recently reported that small amounts of alcohol (e.g. $<30 \%$ ) in low ionic strength buffers can accelerate DNA-directed nanoparticle assembly. ${ }^{27}$ However, the self-aggregation of AuNPs at high alcohol and salt concentrations did not allow a complete understanding of the role of organic solvents in the assembly process. The tendency of AuNP selfaggregation in solvents with a low dielectric constant likely occurs due to the high density of negatively charged DNA immobilized on the AuNP surface resulting in strong electrostatic interactions. On the other hand, we may observe a faster hybridization rate with non-immobilized probes such as molecular beacons. Molecular beacons are engineered DNA hairpins with the two ends labeled with a fluorophore and a quencher, respectively. ${ }^{15,19,28}$ The beacon in the closed hairpin form has low fluorescence. In the presence of target DNA, the hairpin is opened resulting in an increase in the fluorescence. Molecular beacons have been widely used for DNA/RNA detection in medical diagnosis, ${ }^{19,28}$ real-time PCR, and biosensor development. ${ }^{29}$ Over the past 15 years, a number of improvements have been made on the beacon fluorophore, ${ }^{30,31}$ quencher, ${ }^{32-34}$ and the DNA backbone ${ }^{35-37}$ to enhance signal, decrease background, and increase specificity and stability. Varying the solvent composition may provide another factor for molecular beacon engineering.

There are numerous studies regarding the hybridization of DNA in water. ${ }^{1,38-42}$ Since DNA is a polyanion, increasing the salt concentration screens the negative charge resulting in a faster hybridization rate; while increasing the temperature can sometimes decrease the rate. ${ }^{43,44}$ On the other hand, few reports 
exist regarding DNA hybridization in various organic solvents. In one study formamide was shown to accelerate DNA hybridization. ${ }^{45-47}$ In another, formation of an emulsion with the addition of phenol to water also increased the hybridization rate, which was attributed to interfacial adsorption and diffusion. ${ }^{48,49}$ Because of its complexity, however, the mechanism of DNA hybridization is still under debate..$^{50}$

Herein, we report molecular beacon hybridization in nine different organic solvents up to $75 \%(\mathrm{v} / \mathrm{v}$ ). Hybridization of the target DNA with the beacon is achieved in all of the nine solvents. In particular, the rate of hybridization is significantly accelerated in most solvents (e.g. up to 70 -fold in $56 \%$ ethanol). At the same time, DNA melting temperature $\left(\mathrm{T}_{\mathrm{m}}\right)$ decreases in all the solvents. The increased beacon response and decreased $\mathrm{T}_{\mathrm{m}}$ allow better discrimination of mismatched DNA targets. The fast hybridization rates can be explained by the decreased activation energy in the presence of organic solvents.

\section{MATERIALS AND METHODS}

DNA and Chemicals. The molecular beacon DNA was purchased from Gene Link (Hawthorne, NY). The other DNA samples were purchased from Integrated DNA Technologies (Coralville, IA). The DNA sequences and modifications used are shown in Table 1. $\mathrm{NaCl}$ and HEPES for making the buffers were purchased from Mandel Scientific (Guelph, Ontario, Canada). All of the buffers and solutions were made using Millipore water. All of the organic solvents were purchased from VWR (Mississauga, Ontario, Canada) and solvent percentages added are in v/v. 
Table 1. The DNA sequences and modifications used in this work. BHQ1 denotes Black Hole Quencher 1. The mutated nucleotides in Mis1-3 are highlighted by an underline. For the last three entries, the target DNA sequence is embedded in the middle highlighted by an underline.

$\begin{array}{ll}\text { Name } & \text { Sequences and modifications (listed from } 50 \text { to 30) } \\ \text { Beacon } & \text { FAM-GCGAGCCAGGTTCTCTTCACAGATGCGCTCGC-BHQ1 } \\ \text { Target } & \text { ACGCATCTGTGAAGAGACCTGG } \\ \text { Mis1 } & \text { ACGCATCTTTGAAGAGAACCTGGG } \\ \text { Mis2 } & \text { ACGCATCTㄷGAAGAGAACCTGGG } \\ \text { Mis3 } & \text { ACGCATCTÁTGAAGAGAACCTGGG } \\ \text { Mis4 } & \text { CTTCTTTCTTCCCCTTGTTTGTG } \\ \text { 34-mer } & \text { ACACAACGCATCTGTGAAGAGAACCTGGGACACA } \\ \text { 44-mer } & \text { ACACAACACAACGCATCTGTGAAGAGAACCTGGGACACAACACA } \\ \text { 60-mer } & \text { ACAACACAACACAACACAACGCATCTGTGAAGAGAACCTGGGACACAACACAACACAACA }\end{array}$

Kinetic Studies. Most of the kinetic studies were performed using a Molecular Device Spetramax M5 plate reader. The excitation wavelength was set at $485 \mathrm{~nm}$ and emission at $520 \mathrm{~nm}$ was monitored. All operations were performed at room temperature $\left(26^{\circ} \mathrm{C}\right)$. For majority of the experiments, $50 \mathrm{nM}$ of the molecular beacon was dissolved in $300 \mathrm{mM} \mathrm{NaCl}, 10 \mathrm{mM}$ HEPES, pH 7.6 with varying percentages of organic solvents. The fluorescence of this sample was monitored for $2 \mathrm{~min}$. Immediately to this sample 2 $\mu \mathrm{L}$ of target DNA was added (final target concentration $200 \mathrm{nM}$ in a volume of $100 \mu \mathrm{L}$ ) and fluorescence signal was monitored every $10 \mathrm{sec}$ for $5 \mathrm{~min}$. Approximately $16 \mathrm{sec}$ elapsed from the time the target DNA was added to the first reading of the machine. This elapsed time was included for both the kinetic calculations and plotting purposes. All of the kinetic studies were performed in triplicates. The kinetic data shown in Figure 2B were obtained using a PTI fluorometer every $1 \mathrm{sec}$ after addition of the target DNA. The beacon and target DNA concentrations were 1.25 and $12.5 \mathrm{nM}$, respectively.

DNA Melting Curves. The melting curves were collected with a sample volume of $11 \mu \mathrm{L}$ containing 1 $\mu \mathrm{M}$ of the molecular beacon and $4 \mu \mathrm{M}$ of the target DNA. The mixture also contained $300 \mathrm{mM} \mathrm{NaCl}$ and $10 \mathrm{mM}$ HEPES, pH 7.6. The samples were loaded into a 96-well PCR plate and sealed with a heated (105 
$\left.{ }^{\circ} \mathrm{C}\right)$ plastic cover to avoid evaporation. The samples were analyzed using a Bio-Rad CFX96 real time PCR thermocycler. The LED excitation range was set to be $450-490 \mathrm{~nm}$ and the emission at the $520 \mathrm{~nm}$ region was collected (the FAM channel). The instrument was programmed to first anneal the samples from 85 to $6{ }^{\circ} \mathrm{C}$ and then the melting curves were measured from 6 to $95^{\circ} \mathrm{C}$ with $1{ }^{\circ} \mathrm{C}$ increment and 10 sec holding time.

\section{RESULTS AND DISCUSSION}

System Design. For this study, we employed a molecular beacon with a 6-base-pair stem and a 20nucleotide loop. The presence of a target DNA is expected to open the hairpin, therefore producing a fluorescence signal increase. To test the effect of an organic solvent on molecular beacon hybridization, we chose to use ethanol for most of the studies since ethanol is a common laboratory solvent, non-toxic and routinely used for nucleic acid extraction and precipitation. To understand the mechanism of hybridization rate change in organic solvents, DNA melting studies have also been performed and there are two types of melting in the molecular beacon system: the beacon alone melts at a temperature lower than the duplex DNA formed by the beacon and the target DNA, which is the thermodynamic basis for molecular beacon detection. The $\mathrm{T}_{\mathrm{m}}$ of the beacon DNA alone is independent of its concentration since this is an intramolecular transition. However, the $\mathrm{T}_{\mathrm{m}}$ of the duplex DNA is a function of DNA concentrations. ${ }^{51}$ Therefore, the beacon and target DNA concentrations have been kept constant for most of the experiments.

The Effect of Varying Ethanol Percentage. To study the molecular beacon hybridization kinetics, the ethanol concentration was first varied in $300 \mathrm{mM} \mathrm{NaCl}$ with $10 \mathrm{mM}$ HEPES, pH 7.6. In a typical experiment, the fluorescence of $50 \mathrm{nM}$ molecular beacon was monitored for $2 \mathrm{~min}$ prior to the addition of $200 \mathrm{nM}$ target DNA. In the aqueous buffer (no ethanol), it takes more than $10 \mathrm{~min}$ for the fluorescence signal to plateau, as shown in Figure 1A (black curve) and Figure 2B (the $300 \mathrm{mM}$ trace). This rate is typical for molecular beacon detection in aqueous buffers. ${ }^{19}$ The hybridization kinetics become progressively faster as the ethanol content is increased to $56 \%$ (Figure 1A), where the signal saturates in less than $16 \mathrm{sec}$ (the fastest time that can be achieved by manual pipetting and the fluorescence plate 
reader). In the case of $75 \%$ ethanol (pink curve), no fluorescence increase was observed and the background fluorescence was lower compared to other samples. This suggests that most of the beacon DNA was in the hairpin conformation and addition of the target DNA failed to form the duplex structure. DNA is known to dehydrate and aggregate in the presence of high amounts of alcohol and salt rather than forming Watson-Crick base pairing interactions. ${ }^{52}$ As a result, we chose to perform most studies using $56 \%$ ethanol to achieve both high reaction rates as well as specificity.

When the ethanol percentage was varied from 0 to $56 \%$, the final fluorescence intensities after addition of the target DNA saturated at similar intensities if enough time is allowed to elapse. In addition, the initial fluorescence intensities are also similar for these samples (Figure 1A and Figure 2B, the $300 \mathrm{mM}$ trace). Since the observed fluorescence intensities are directly related to the equilibrium between the hairpin and the duplex state, ethanol did not significantly shift the equilibrium of the molecular beacon/target hybridization reaction. The rapid fluorescence increase suggests that the hybridization rate is increased. To maintain a similar equilibrium constant, the reverse reaction rate must also increase to a similar extent. Therefore, ethanol functions as a catalyst for molecular beacon hybridization.

Since with a respective concentration of 50 and $200 \mathrm{nM}$ for the molecular beacon and target DNA, the reaction was completed in the first $16 \mathrm{sec}$, in order to quantitatively understand the rapid kinetics of hybridization, we decreased the concentration of the beacon and target DNA to obtain data points in the initial stage of the reaction. The concentration of the molecular beacon was decreased to $1.25 \mathrm{nM}$ and the target DNA to $12.5 \mathrm{nM}$ in $56 \%$ ethanol. As shown in Figure 1B (black curve), the decreased DNA concentrations allowed us to observe the initial kinetics profile. In particular, this pseudo-first order reaction condition (target DNA: molecular beacon $=10: 1$ ) allowed us to fit the kinetics data with the equation $y=y_{0}+a\left(1-e^{-b t}\right)$, where $b$ is the rate of the reaction. A rate of $2.5 \mathrm{~min}^{-1}$ for DNA hybridization was determined for the sample in $56 \%$ ethanol and a rate of $0.035 \mathrm{~min}^{-1}$ was determined with no ethanol $\left(R^{2}=0.98\right.$ for both fittings), giving a rate enhancement of $\sim 70$-fold in $56 \%$ ethanol. 

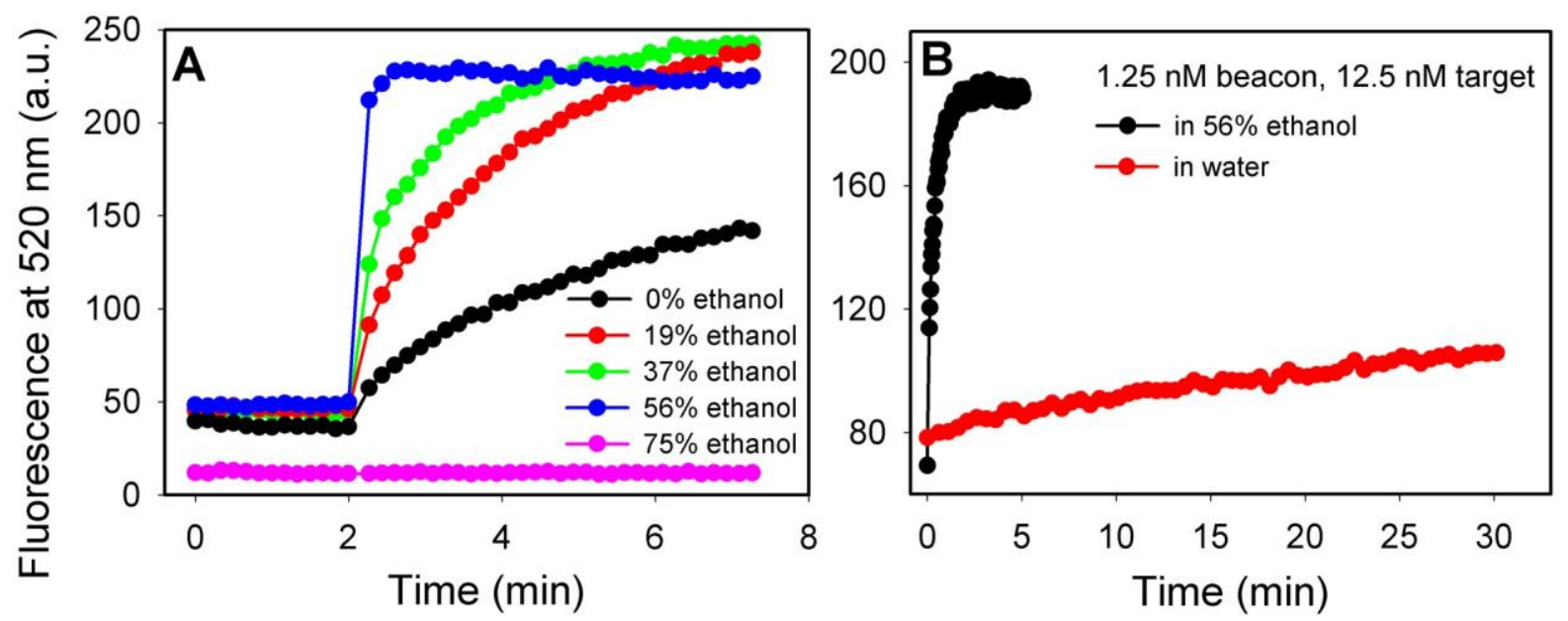

Figure 1. The kinetics of molecular beacon hybridization in $300 \mathrm{mM} \mathrm{NaCl} 10 \mathrm{mM}$ HEPES, pH 7.6 with different ethanol percentages. (A) With $50 \mathrm{nM}$ molecular beacon and $200 \mathrm{nM}$ target DNA. DNA was added at time 2 min. (B) With $1.25 \mathrm{nM}$ molecular beacon and $12.5 \mathrm{nM}$ target DNA.

Effect of Salt Concentration. Since DNA is a polyanion, electrolytes such as $\mathrm{NaCl}$ play a crucial role in the hybridization kinetics. With the optimal ethanol concentration of $56 \%$, we tested the effect of salt. As shown in Figure 2A, very little signal increase was observed if no $\mathrm{NaCl}$ was present, and this is consistent with the notion that salt is required for DNA hybridization. With increasing $\mathrm{NaCl}$ concentration, the final fluorescence signal increased, suggesting that $\mathrm{NaCl}$ can control the reaction equilibrium and a higher salt concentration favors duplex formation. The kinetics of hybridization were very fast with $>100$ $\mathrm{mM} \mathrm{NaCl}$. For comparison, Figure 2B shows the salt-dependent experiments in the aqueous buffer (no ethanol). The rates were much slower requiring the hybridization reaction to be monitored for $1 \mathrm{hr}$. The hybridization rate increased until $\mathrm{NaCl}$ was increased to $200 \mathrm{mM}$. Further increase in $\mathrm{NaCl}$ had very little effect on the rate or final fluorescence intensity. Therefore increasing $\mathrm{NaCl}$ in water can accelerate molecular beacon hybridization, but there is a limit ( $200 \mathrm{mM}$ in this case). Importantly, ethanol induced acceleration shown in Figure $1 \mathrm{~A}$ (with $300 \mathrm{mM} \mathrm{NaCl}$ ) is on top of the $\mathrm{NaCl}$ effect. We also noticed that the final fluorescence intensities in high salt buffers (e.g. > $100 \mathrm{mM}$ in Figure 2) were higher for water than for ethanol. This was attributed to the decreased $T_{m}$ in ethanol and therefore less duplex DNA was formed (vide infra). 

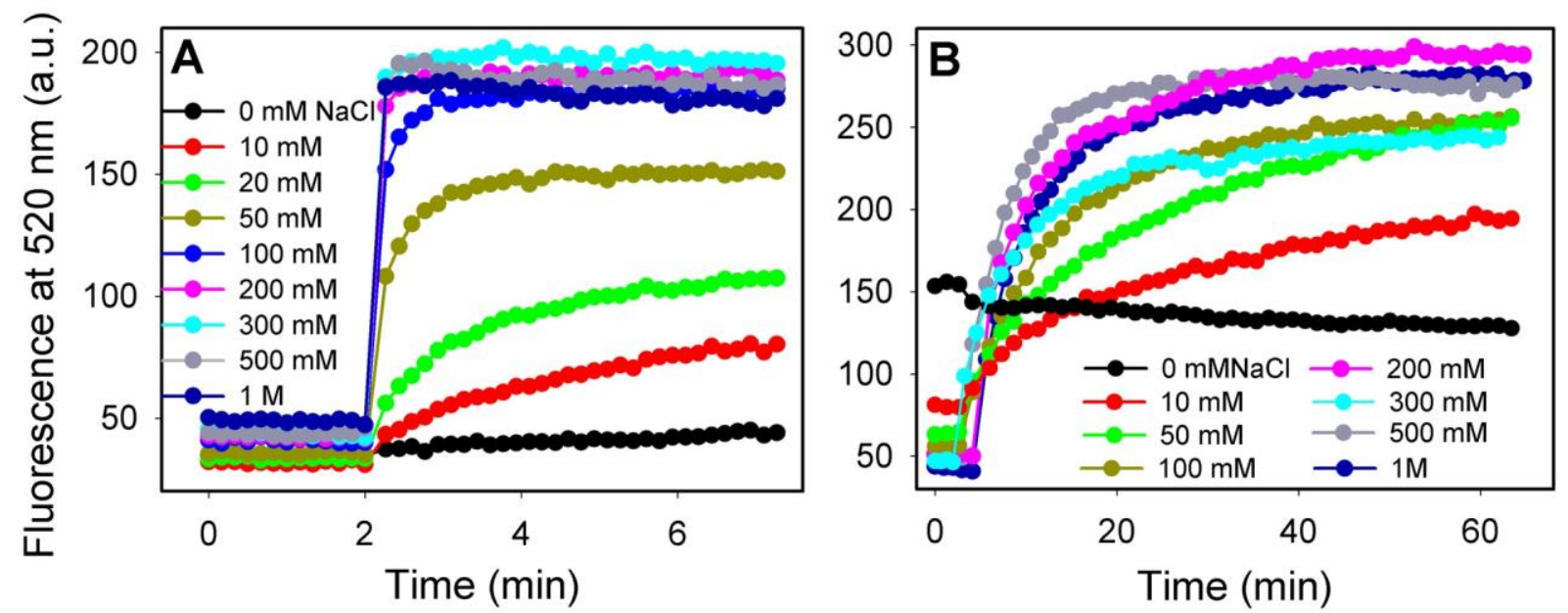

Figure 2. Effect of increasing $\mathrm{NaCl}$ concentration on DNA hybridization in the aqueous buffer (A) and in $56 \%$ ethanol (B). Note that fluorescence was monitored after addition of target DNA for 5 min (A) or $1 \mathrm{hr}(\mathrm{B})$.

Mismatched DNA Targets. For sequence selective DNA detection, an important aspect is to distinguish single base mismatches. To test the target specificity of our molecular beacon in ethanol, four DNA strands containing mismatches were also studied. As shown in Figure 3A, fast hybridization rates were observed for the three target DNAs containing single base mismatches (Mis1-3, see Table 1 for the location of mismatches). However, the final fluorescence intensities were lower compared to the perfectly matched target. This experiment further supported that the reaction equilibrium can be quickly established in ethanol. For a completely non-target sequence (Mis4), no fluorescence enhancement was observed. Therefore, the molecular beacon in ethanol was capable of selectively binding to its target DNA and the observed fluorescence enhancement was due to specific DNA hybridization instead of non-specific interactions. Interestingly, the mismatched and matched DNA targets behaved quite similarly in the aqueous buffer. As shown in Figure 3B, two of the mismatched targets (Mis2 and Mis3) appear to hybridize slower compared to the perfectly matched one. However, Mis1 showed a similar hybridization rate to the matched target. It is also difficult to distinguish these DNAs containing single base mismatches from the perfect target in water by monitoring the final fluorescence; they all showed a similar final 
fluorescence (Figure 3B). These results indicate that ethanol also allows better recognition of mismatched DNA strands.

To better understand the observed effects, DNA melting experiments have been performed. First, the beacon was allowed to form a duplex with the target DNA and then the $T_{m}$ of this duplex was measured. A $\mathrm{T}_{\mathrm{m}}$ value of $71{ }^{\circ} \mathrm{C}$ in the $300 \mathrm{mM} \mathrm{NaCl}$ aqueous buffer was obtained for the target DNA. On the other hand, when DNA strands contained single base mismatches, the $\mathrm{T}_{\mathrm{m}}$ values dropped to $\sim 60^{\circ} \mathrm{C}$. Since these $\mathrm{T}_{\mathrm{m}}$ values were much higher than room temperature $\left(26^{\circ} \mathrm{C}\right)$, at which the experiment was conducted, the decreased stability brought by the mismatches was not obvious. In $56 \%$ ethanol, a $\mathrm{T}_{\mathrm{m}}$ of $50{ }^{\circ} \mathrm{C}$ was observed with the perfectly matched target DNA and for mismatched targets, $\mathrm{T}_{\mathrm{m}}$ 's close to $38^{\circ} \mathrm{C}$ were obtained, which were close to the experimental temperature of $26^{\circ} \mathrm{C}$. Therefore, the fraction of the beacon in the duplex form was much more sensitive to the $T_{m}$ in ethanol. While it is possible to decrease the $T_{m}$ of DNA by simply decreasing the salt concentration, the hybridization kinetics also decreases. In ethanol, however, we have achieved increased hybridization kinetics with high target specificity.

For detection of biological DNA samples, it is likely that the molecular beacon can only probe a small portion within a long DNA target. To test the effect of target DNA length, DNA strands made up of 60, 44, and 32-mer with the target sequence embedded within the strands were also tested. As shown in Figure 3C all of the DNAs showed a fast hybridization rate and similar final fluorescence intensity in $56 \%$ ethanol. For comparison purposes, the hybridization rates were also monitored in water (Figure 3D). The hybridization rates were slightly faster with two shorter targets compared to the longest one, but overall the rates were significantly slower compared to that in ethanol. The fast hybridization could be important for very long DNA samples to allow a shorter incubation time. 

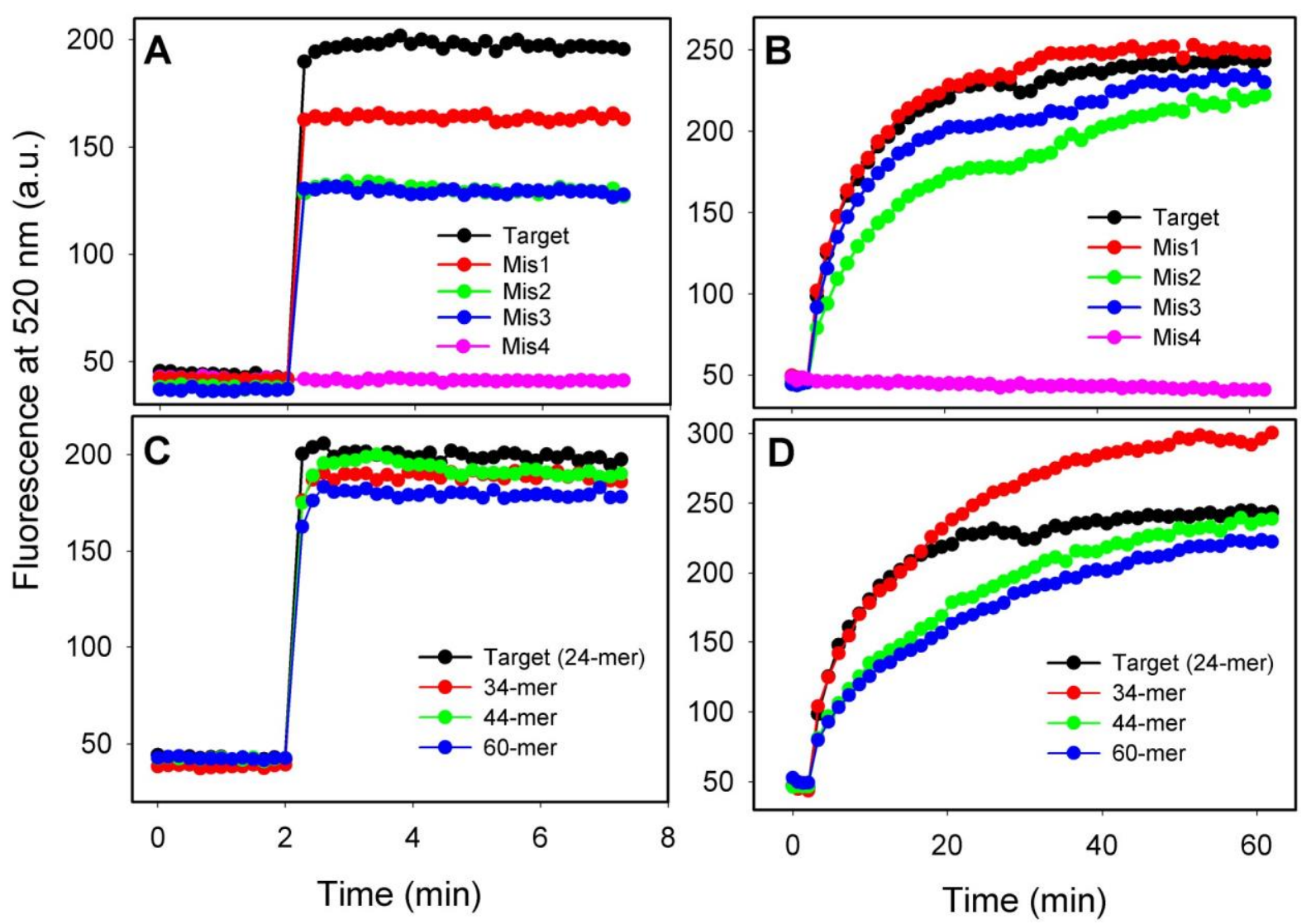

Figure 3. Detection of target DNA sequences containing mismatches in $56 \%$ ethanol (A) and water (B). Detection of long target DNA sequences in 56\% ethanol (C) and water (D). All of the samples contained $300 \mathrm{mM} \mathrm{NaCl}, 10 \mathrm{mM}$ HEPES, pH 7.6.

Molecular Beacon Hybridization in Other Organic Solvents. While ethanol is an important solvent for DNA manipulation, DNA can also be dissolved in many other organic solvents. To systematically test the effect of organic solvents on hybridization kinetics, we performed solvent concentrationdependent assays using eight other common laboratory solvents (Figure 4). Significant rate enhancements were observed for most solvents within a certain concentration range. Methanol was slightly less effective compared to ethanol (Figure 4A). Fast hybridization was observed only at $75 \%$ and the final fluorescence intensity was also lower. Although isopropanol showed a rapid enhancement at 56\%, the final fluorescence at that alcohol concentration was also quite low (Figure 4B). Acetonitrile showed rapid hybridization even at 37\% (Figure 4C). Although acetonitrile is miscible with water alone, phase separation occurs at percentages higher than $56 \%$ in the presence of $300 \mathrm{mM} \mathrm{NaCl}$. Therefore, higher 
concentrations were not tested for this particular solvent. Formamide, dimethylformamide (DMF), and dimethyl sulfoxide (DMSO) showed a quite similar behavior (Figure 4D-F); all gave an optimal rate at $37 \%$. Ethylene glycol showed only a moderate rate enhancement compared to other solvents, whereas glycerol did not show any obvious rate enhancement. These experiments indicate that the molecular beacon detection can occur in many organic solvents within a certain percentage range and a significant rate increase can be observed. However, if the percentage of an organic solvent is too high, hybridization is inhibited. 

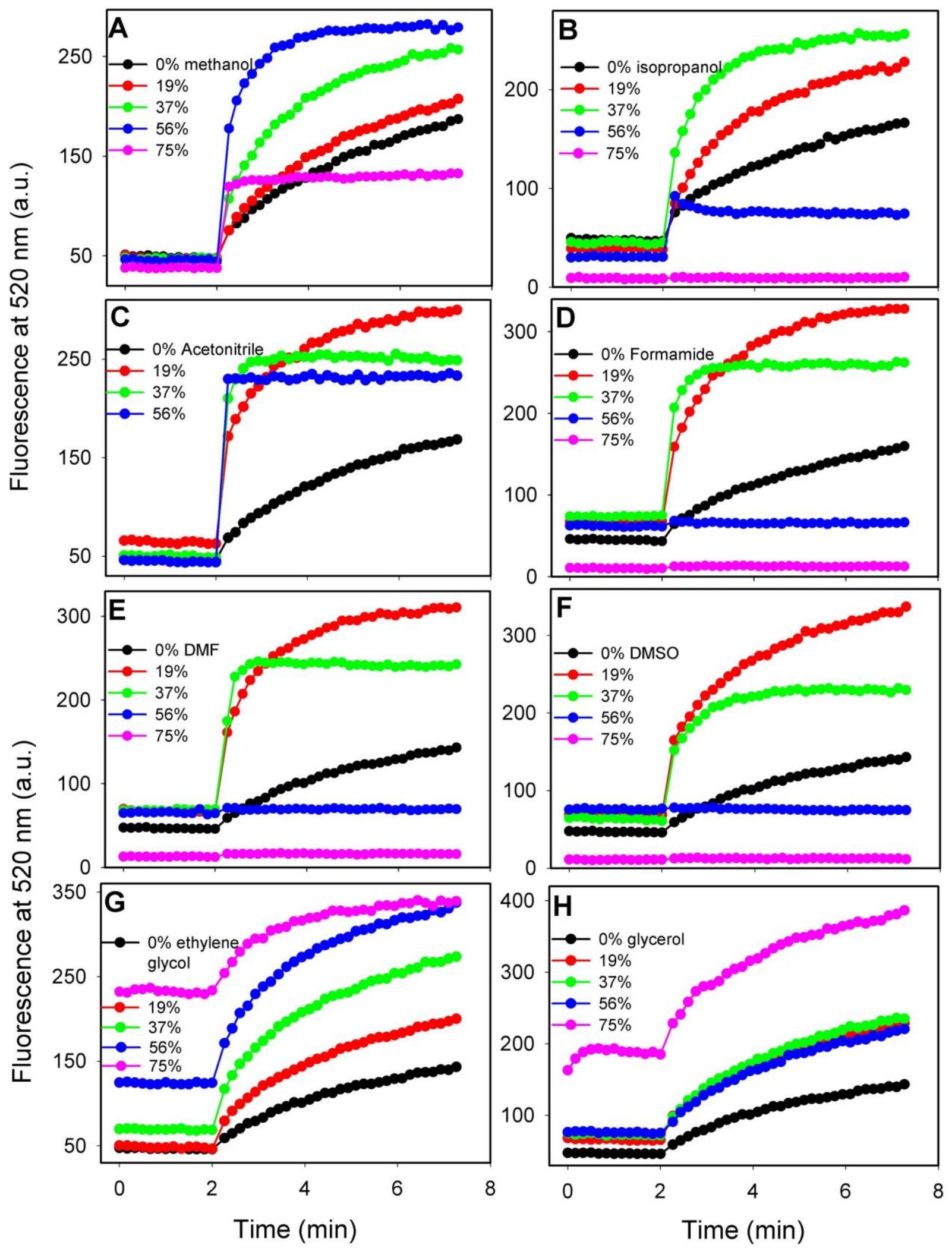

Figure 4. Kinetics of molecular beacon and target DNA hybridization in various percentages of organic solvents in $300 \mathrm{mM} \mathrm{NaCl}, 10 \mathrm{mM}$ HEPES, pH 7.6. The target DNA was added after $2 \mathrm{~min}$. 
Melting Curves. To further understand the observed hybridization kinetics, the melting curves of the beacon-target duplex were measured in $300 \mathrm{mM} \mathrm{NaCl}, 10 \mathrm{mM}$ HEPES, pH 7.6 with varying percentages of organic solvents. There is a decrease in $\mathrm{T}_{\mathrm{m}}$ with increasing solvent percentages, and this trend appears to be linear for most solvents (Figure 5). This is in good agreement with the literature reports where $\mathrm{T}_{\mathrm{m}}$ was measured by other methods. ${ }^{53,54}$ Only four solvents have been measured up to $75 \%$ (methanol, glycerol, ethylene glycol, and formamide). The rest of the solvents failed to show a melting transition at high concentrations and the plots were stopped at the highest solvent concentration where a melting transition can still be observed.

In general, solvents that were effective in decreasing the $\mathrm{T}_{\mathrm{m}}$ of DNA, such as the alcohols, formamide, ACN, and DMF were also quite effective in accelerating the hybridization kinetics. Ethylene glycol and glycerol showed a smaller $\mathrm{T}_{\mathrm{m}}$ slope and the kinetics increase were also small. Viscosity may also play an important role for some of the solvents such as glycerol. Drastically increasing the viscosity should disfavor hybridization, which may explain why glycerol showed little increase on the hybridization rate even with decreased $\mathrm{T}_{\mathrm{m}}$. Some solvents such as those tested alcohols are known to precipitate DNA and cause DNA aggregation at high solvent concentrations. ${ }^{21,52}$ For most tested solvents at $75 \%$, for example, very little fluorescence change was observed in the presence of the target DNA (Figure 4), possibly due to after DNA aggregation/precipitation, the diffusion and binding become more difficult. For most tested solvents under relatively dilute conditions (e.g. less than $50-60 \%$ ethanol), ${ }^{52}$ DNA is not known to aggregate and therefore, the observed kinetics change should be independent of such processes. Based on the $\mathrm{T}_{\mathrm{m}}$ and kinetic data, the effect of organic solvents on the hybridization rate appears to stem from the decrease of activation energy for the hybridization and de-hybridization (or melting) reaction to a similar extent, such that the rate is enhanced without significantly shift the reaction equilibrium. 


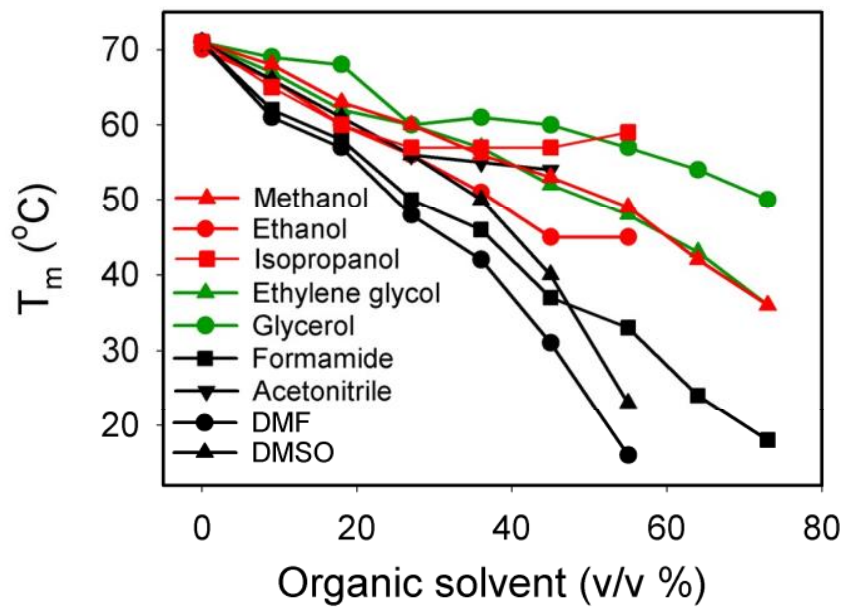

Figure 5. The melting temperatures of the molecular beacon hybridized to the target DNA in $300 \mathrm{mM}$ $\mathrm{NaCl}, 10 \mathrm{mM}$ HEPES, $\mathrm{pH} 7.6$ with various percentages of organic solvents.

CONCLUSIONS. In summary, molecular beacon hybridization can be carried out in a wide range of organic solvents. A significant hybridization rate enhancement was observed for most solvents. These accelerated hybridization reactions are attributed to the reduced activation energy barrier for the hybridization reaction. At the same time, the reaction specificity is still maintained. This work suggests that DNA-based probes can be used for applications where organic solvents must be involved, and at the same time, organic solvents can be intentionally added to improve the performance of such assays.

ACKNOWLEDGMENT. We thank the Honek and Palmer groups at the University Of Waterloo for the use of fluorometers. Funding for this work is from the University of Waterloo and the Natural Sciences and Engineering Research Council (NSERC) of Canada.

\section{REFERENCES}

(1) Wetmur, J. G. Crit. Rev. Biochem. Mol. Biol. 1991, 26, 227.

(2) Chan, V.; Graves, D. J.; McKenzie, S. E. Biophys. J. 1995, 69, 2243.

(3) Steel, A. B.; Levicky, R. L.; Herne, T. M.; Tarlov, M. J. Biophys. J. 2000, 79, 975.

(4) Peterson, A. W.; Heaton, R. J.; Georgiadis, R. M. Nucleic Acids Res. 2001, 29, 5163.

(5) Tawa, K.; Yao, D. F.; Knoll, W. Biosens. Bioelectron. 2005, 21, 322.

(6) Gao, Y.; Wolf, L. K.; Georgiadis, R. M. Nucleic Acids Res. 2006, 34, 3370. 
(7) Spring, B. Q.; Clegg, R. M. J Phys Chem B 2007, 111, 10040.

(8) Seeman, N. C. Nature 2003, 421, 427.

(9) Mirkin, C. A.; Letsinger, R. L.; Mucic, R. C.; Storhoff, J. J. Nature 1996, 382, 607.

(10) Alivisatos, A. P.; Johnsson, K. P.; Peng, X.; Wilson, T. E.; Loweth, C. J.; Bruchez, M. P., Jr;

Schultz, P. G. Nature 1996, 382, 609.

(11) Lin, C.; Liu, Y.; Yan, H. Biochemistry 2009, 48, 1663.

(12) Sharma, J.; Chhabra, R.; Cheng, A.; Brownell, J.; Liu, Y.; Yan, H. Science 2009, 323, 112.

(13) Willner, I.; Shlyahovsky, B.; Zayats, M.; Willner, B. Chem. Soc. Rev. 2008, 37, 1153.

(14) Liu, J.; Cao, Z.; Lu, Y. Chem. Rev. 2009, 109, 1948.

(15) Wang, K. M.; Tang, Z. W.; Yang, C. Y. J.; Kim, Y. M.; Fang, X. H.; Li, W.; Wu, Y. R.; Medley, C. D.; Cao, Z. H.; Li, J.; Colon, P.; Lin, H.; Tan, W. H. Angew. Chem. Int. Ed. 2009, 48, 856.

(16) Navani, N. K.; Li, Y. Curr. Opin. Chem. Biol. 2006, 10, 272.

(17) Stoughton, R. B. Ann. Rev. Biochem. 2005, 74, 53.

(18) Wong, M. L.; Medrano, J. F. BioTechniques 2005, 39, 75.

(19) Tyagi, S.; Kramer, F. R. Nat. Biotechnol. 1996, 14, 303.

(20) Rosi, N. L.; Mirkin, C. A. Chem. Rev. 2005, 105, 1547.

(21) Herskovits, T.; Singer, S. J. Arch. Biochem. Biophys. 1961, 94, 99.

(22) Gupta, M. N. European Journal of Biochemistry 1992, 203, 25.

(23) Carrea, G.; Riva, S. Angew. Chem. Int. Ed. 2000, 39, 2226.

(24) Matsui, J.; Takayose, M.; Akamatsu, K.; Nawafune, H.; Tamaki, K.; Sugimoto, N. Analyst 2009, 134,80 .

(25) Rozenman, M. M.; Kanan, M. W.; Liu, D. R. J. Am. Chem. Soc. 2007, 129, 14933.

(26) Angelatos, A. S.; Johnston, A. P. R.; Wang, Y. J.; Caruso, F. Langmuir 2007, 23, 4554.

(27) Smith, B. D.; Liu, J. J. Am. Chem. Soc. 2010, 132, 6300.

(28) Tyagi, S.; Bratu, D. P.; Kramer, F. R. Nat. Biotechnol. 1998, 16, 49.

(29) Fang, X.; Liu, X.; Schuster, S.; Tan, W. J. Am. Chem. Soc. 1999, 121, 2921.

(30) Yang, C. Y. J.; Pinto, M.; Schanze, K.; Tan, W. H. Angew. Chem. Int. Ed. 2005, 44, 2572.

(31) Conlon, P.; Yang, C. Y. J.; Wu, Y. R.; Chen, Y.; Martinez, K.; Kim, Y. M.; Stevens, N.; Marti, A. A.; Jockusch, S.; Turro, N. J.; Tan, W. H. J. Am. Chem. Soc. 2008, 130, 336.

(32) Dubertret, B.; Calame, M.; Libchaber, A. J. Nat. Biotechnol. 2001, 19, 365.

(33) Yang, C. Y. J.; Lin, H.; Tan, W. H. J. Am. Chem. Soc. 2005, 127, 12772.

(34) Wang, Y. X.; Li, J. S.; Jin, J. Y.; Wang, H.; Tang, H. X.; Yang, R. H.; Wang, K. M. Anal. Chem. 2009, 81, 9703. 
(35) Wang, L.; Yang, C. Y. J.; Medley, C. D.; Benner, S. A.; Tan, W. H. J. Am. Chem. Soc. 2005, 127, 15664.

(36) Tsourkas, A.; Behlke, M. A.; Bao, G. Nucleic Acids Res. 2002, 30, 5168.

(37) Shah, R.; El-Deiry, W. S. Cancer Biology \& Therapy 2004, 3, 871.

(38) Wetmur, J. G. Annu. Rev. Biophys. Bioeng. 1976, 5, 337.

(39) Chen, C. L.; Wang, W. J.; Wang, Z.; Wei, F.; Zhao, X. S. Nucleic Acids Res. 2007, 35, 2875.

(40) Chu, Y. G.; Tinoco, I. Biopolymers 1983, 22, 1235.

(41) Kushon, S. A.; Jordan, J. P.; Seifert, J. L.; Nielsen, H.; Nielsen, P. E.; Armitage, B. A. J. Am. Chem. Soc. 2001, 123, 10805.

(42) Chien, F. C.; Liu, J. S.; Su, H. J.; Kao, L. A.; Chiou, C. F.; Chen, W. Y.; Chen, S. J. Chem. Phys. Lett. 2004, 397, 429.

(43) Porschke, D.; Uhlenbec.Oc; Martin, F. H. Biopolymers 1973, 12, 1313.

(44) Porschke, D.; Eigen, M. J. Mol. Biol. 1971, 62, 361.

(45) Bonner, J.; Kung, G.; Bekhor, I. Biochemistry 1967, 6, 3650.

(46) McConaug.Bl; Laird, C. D.; McCarthy, B. J. Biochemistry 1969, 8, 3289.

(47) Weiss, S. B.; Hsu, W. T.; Foft, J. W.; Scherber.Nh. Proc. Natl. Acad. Sci. U.S.A. 1968, 61, 114.

(48) Kohne, D. E.; Levison, S. A.; Byers, M. J. Biochemistry 1977, 16, 5329.

(49) Goldar, A.; Sikorav, J. L. Eur. Phys. J. E 2004, 14, 211.

(50) Sikorav, J. L.; Orland, H.; Braslau, A. J Phys Chem B 2009, 113, 3715.

(51) SantaLucia, J. Proc. Natl. Acad. Sci. U.S.A. 1998, 95, 1460.

(52) Piskur, J.; Rupprecht, A. Febs Letters 1995, 375, 174.

(53) Klump, H.; Burkart, W. Biochim. Biophys. Acta 1977, 475, 601.

(54) Hickey, D. R.; Turner, D. H. Biochemistry 1985, 24, 2086. 